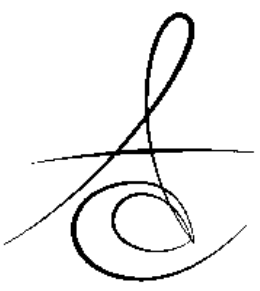

\title{
RADYOTERAPİ GÖRMÜŞ OLAN HASTANIN TELESKOBİK TUTUCULU HAREKETLİ BÖLÜMLÜ PROTEZ İLE TEDAVİSİ : OLGU SUNUMU
}

\section{TREATMENT OF A RADIOTHERAPY PATIENT WITH A TELESCOBIC RETAINING REMOVABLE PARTIAL DENTURE: A CASE REPORT}

\author{
Arş. Gör. Dt. Harun Reşit BAL ${ }^{*}$
}

\author{
Prof. Dr. Nuran YANIKOĞLU*
}

Makale Kodu/Article code: 3620

Makale Gönderilme tarihi: 30.03 .2018

Kabul Tarihi: 26.06.2018

\section{öz}

Teleskop tutuculu protezler, diş-doku destekli, diş destekli ve implant-doku destekli vakalarda hasta konforunu ve memnuniyetini arttırdığından dolayı günümüzde çok fazla kullanılmaktadır. Teleskopik kronların biyomekaniği, protezlere iyi bir tutunma ve stabilite sağlamaya yardımcı olur. Destek dişlerin splintlenmesi, destek dişin kaybında tamir kolaylığı, temizlenmesinin kolay olması gibi faktörler teleskobik tutuculu protezlerin diğer avantajlarındandır. Bu olgu sunumunda kemoterapi ve radyoterapi tedavisi almış, 46 yaşındaki bayan hastamızın alt çenesine yapılan teleskobik tutuculu hareketli bölümlü protezin klinik uygulaması sunulmuştur. Hastamızın tedavisine radyotarapiden yaklaşık bir yıl sonra başlanmıştır. Medikal Onkoloji ve Radyasyon Onkolojiden konsültasyon alınarak periodontal kemik kaybı olan dişlerin çekimleri yapılmıştır. Ağızda kalan mevcut dişlere periodontal faz 1 tedavi uygulanmıştır. Teleskobik kuron için destek alınacak dişlerin kanal tedavisini takiben preperasyonları yapılmıştır. Preperasyonu yapılan dişlerde dişeti retraksiyonu yapıldı ve ölçüsü alındı. Dental model üzerinde primer kuronlar yapılmıştır. Hareketli bölümlü protezin yapılması için primer kuronlar ile birlikte ölçü alınmıştır. Provalar ve laboratuvar işlemleri tamamlandıktan sonra protez hastaya teslim edilmiştir. Periyodik olarak 18 ay boyunca klinik ve radyografik kontrol seansları yapılmıştır.

Anahtar Kelimeler: Radyoterapi, Teleskopik kuron, Hareketli bölümlü protez, Primer kuron, Sekonder kuron

\section{ABSTRACT}

Telescopic retaining prostheses are used extensively nowadays due to increased patient comfort and satisfaction in dental-tissue supported, dental assisted and implant-tissue assisted cases. The biomechanics of telescopic crowns aid in providing a good retention and stability to the prosthesis. Other advantages of telescopic retaining prostheses include splinting of the supporting teeth, ease of repair of the supporting teeth, and ease of cleaning. In this case report, we present a clinical application of a telescopic moving segmental prosthesis to the lower jaw of a 46-year-old female patient who received chemotherapy and radiotherapy. Radiotherapy was started about one year after the treatment of our patient. Medical Oncology and Radiation Oncology consultations were taken and teeth with periodontal bone loss were taken. Periodontal phase 1 treatment was applied to the existing teeth in the mouth. Preparations were made following canal treatment of the teeth to be used for telescopic crown. The preperation teeth were measured and primer crowns were made. For moving parted prosthesis, measurements were taken together with the primer crowns. Prosthetics have been delivered since the prostate and laboratory procedures were performed. Clinical and radiographic examinations during the 18 months follow-up period showed that the patient was satisfied with esthetics, function and fundamentals of the telescope-assisted partial prosthesis.

Key Words: Radiotherapy, Telescopic crown, Removable partial denture, Primer crowns, Seconder crown

\footnotetext{
*Atatürk Üniversitesi, Diş Hekimliği Fakültesi, Protetik Diş Tedavisi AD, Erzurum
} 


\section{GİRİş}

Teleskobik kuron sistemleri, 20. yüzyılın başlarından itibaren gerek fonksiyonel gerekse estetik olarak hareketli bölümlü protezler (HBP) de başarılı bir şekilde kullanılmaktadır ${ }^{1,2}$. Diş sayısının yetersiz ve fizyolojik yada patalojik aşınma sonucu kuron boyu azalmış vakalarda teleskop kuron tutuculu hareketli bölümlü protezler konvansiyonel protezlere alternatif bir tedavi yaklaşımıdır². Teleskop kuronlar primer(iç kuron, birincil, patris, kapişon) ve sekonder(dış kuron, ikincil, matris) kuron olmak üzere iki parçadan oluşmaktadır ${ }^{2,3}$. Bunlardan primer kuron destek dişe kalıcı olarak simante edilir ve hastanın ağzında sabit kalırken, sekonder teleskopik kuron ise protezin iskeletine bağlıdır ve hareketli protez ile birlikte çıkartılabilir. Primer kuron mevcut destek dişi dış etkenlere karşı korur, sekonder kuronlar için retansiyon ve stabilizasyon sağlar ${ }^{1}$. Primer kuronlar giriş yolu problemin giderilmesinde etkindirler ${ }^{2}$.

Tutuculukta primer etki kontakt duvarların konik düzenidir. Koniklik açısı ortalama 6 derecedir ${ }^{5}$. Teleskopik sistemlerde retansiyon ve stabilite destek dişlerin sayıları ve dental arktaki dağılımları ile ilişkilidir. Destek dişlerin simetrik dağılımları stabilite ve retansiyon yönüyle önem kazanmaktadır ${ }^{1}$. Retansiyon primer ile sekonder kuron arasındaki sürtünme kuvveti ile doğru orantılıdır. Sürtünme kuvveti artarsa tutuculuk artar. Sürtünme kuvveti de koniklik açısıyla ters orantılıdır. Koniklik açısı azalırsa sürtünme kuvveti artar dolayısıyla retansiyon da orantılı olarak artar ${ }^{6}$. Koniklik açısı mevcut dişlere göre belirlenmeli, dişlerin destek kuron boyu yeterli ise koniklik açısı arttırılmalı, kuron boyu yetersiz ise 2-5 derecelik koniklik açısı kullanılmamalıdır ${ }^{7}$. Birincil ve ikincil kuronlar sürtünme kuvvetinin etkisiyle ilişkiye girdiğinde restorasyonda splintleme etkisi oluşmaktadır. Dolayısıyla teloskobik sistemler periodontal sağlığı arttırmaktadır ${ }^{6}$.

Sabit protezler prognozu şüpheli olan vakalarda problemler çıkartabilir ve destek dişlerin prognozunu olumsuz yönde etkileyebilir. Bu tür vakalarda tamir kolaylığı gibi avantajları olan TTP'ler kullanılabilir ${ }^{1}$. Tamir edilebilmesi de hastaya maliyet ve zaman konusunda avantajlar sağlar.

Primer kuronlar desteğe simante edilir, sekonder kuronlar ise protezin iskeleti ile splintlenmiştir. dolayısıyla hasta TTP'yi kolaylıkla ağzından çıkarabilir. TTP, simante edilmiş primer kuronlar ve dişeti bölgeleri kolaylıkla temizlenebildiği için oral hijyen ve periodontal sağlık yükselir. Bu olguyu sunmamızdaki amacımız, teleskop tutuculu protezlerin yapımını anlatmak ve bu tür protezlerin sabit protez isteyen ancak sistemik, anatomik ve ekonomik sebeplerden dolayı yaptıramayan hastalarda alternatif bir protez olduğunu vaka raporu ile göstermektir. Çalışmanın hipotezi ise teleskobik tutuculu protezlerin estetik, fonksiyon, fonasyonunun klinik olarak başarısını ve uzun vadeli başarısını araştırmaktır.

\section{OLGU SUNUMU}

46 yaşındaki bayan hastamız eksik dişlerini tamamlattırmak için Atatürk Üniversitesi Diş Hekimliği Fakültesi Protetik Diş Tedavisi Anabilim Dalı kliniğimize başvurmuştur. Anamnezinde dört yıl öncesinde 3 . Derecede meme kanseri tanısı aldığını, 24 hafta kemoterapi tedavisi, 27 gün radyoterapi tedavisi aldığını öğrendik. Hastamız 2015 ocak ayında tedavisinin bittiğini periyodik kontrollerini yaptırdığını bildirdi. Klinik ve radyolojik muayenesi kliniğimizde yapılmıştır. $\mathrm{Bu}$ muayene sonucunda restore edilemeyecek kadar madde kaybı olan; maksiller sağ birinci ve ikinci küçük azı, maksiller sol birinci küçük azı dişleri, mobilite derecesi fazla olan mandibular sağ sol santral ve lateral dişlerin Çene Cerrahisi kliniğimizde Medikal Onkoloji ve Radyasyon Onkolojiden konsültasyon istenerek çekimleri yapılmıştır (Resim 1). Mandibular sağ kanin ve ikinci premolar, sol birinci premolar dişlere Endodonti kliniğinimizde kanal tedavisi yapılmıştır. Ağızda kalan mevcut dişlere periodontal faz 1 tedavi uygulandı. 45 günlük iyileşme sürecinden sonra protetik tedavi aşamasına geçildi (Resim 2).

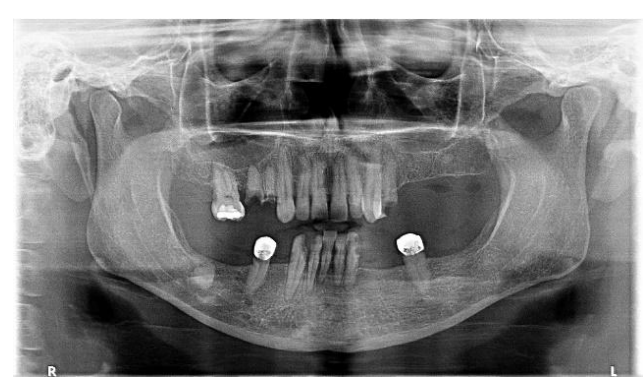

Resim 1. Hastanın Ortopantografisi 


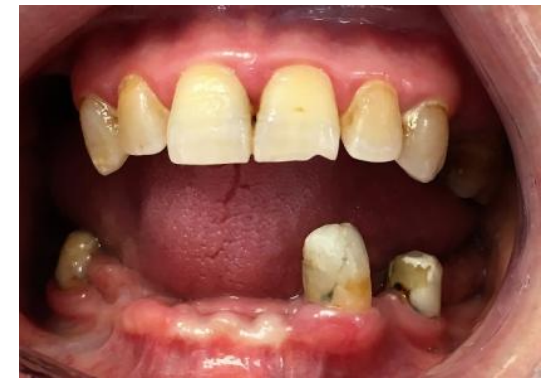

Resim 2. Protetik hazırlık yaptıktan sonraki ağız içi görüntü

Hastanın mevcut dişleri değerlendirilerek hastaya implant üstü sabit protez, overdenture protez, konvansiyonel hareketli bölümlü protez ve hassas bağlantılı protez seçenekleri sunuldu. Kemoterapi ve Radyoterapi tedavisi aldığından dolayı implant üstü tedavinin kontrendike olduğu anlatılmıştır. İskelet hareketli bölümlü protezi de estetik beklentisini karşılamayacağından dolayı kabul etmedi. Hastamızın üst çenesinde estetik kaygıdan dolayı poliamid kaideli (deflex) hareketli bölümlü protez; alt çenesine de teleskobik tutuculu hareketli bölümlü protez planlandı.

Teleskobik kuron için mandibular sağ kanin ve ikinci premolar, sol birinci premolar dişlerin preperasyonu yapıldı. Elastomerik ölçü maddesi (ELİT HD PUTTY, Zhermack, İtalya) kullanılarak prepare dişlerin ölçüsü alındı. Primer kuronun yapılması için laboratuvarda alçı model elde edildi. $\mathrm{Co} / \mathrm{Cr}$ materyalinden primer kuronlar yapıldı. Primer kuronlar ağızda prova edildi (Resim 3). Primer kuronlar üzerinden irreversible hidrokolloid ölçü maddesi(3M ESPE, Impregum penta soft, ABD) ile laboratuvarda hazırlanan kişisel ölçü kaşı̆̆ kullanılarak ölçü alındı, içinde primer kuronların da bulunduğu ölçüden elde edilen ana modeller üzerinde sekonder kuronlar ve sekonder kuronları splintleyen iskelet döküm hazırlanmıştır (Resim 4).

Sekonder kuronlarla birlikte alt iskeletin provası ve fotoplakdan (individo Voco, Almanya) yapılmış üst çene kaidesinin provası yapıldı. Okluzal ve sentrik ilişkinin tespiti için mumlu kapanış alındı. Laboratuvara aktarılan kaydedilmiş kapanışa uygun olarak diş dizimi yapılmıştır. Dişli prova aşamasında dişler ve kaideler fonksiyon, fonasyon ve estetik açısından kontrol edilmiş ve sonrasında protezin bitim işlemi gerçekleştirilmiştir. Hastanın üst çenesine, tam otomatik Deflex Enjeksiyon Makinesinde termoplastik enjeksiyon yöntemi kullanılarak yarı-esnek ve estetik özellikli yeni nesil poliamid materyalinden deflex protez yapılmıştır (Resim 5).
Primer kuronlar cam ionemer siman(Meron, Voco, Almanya) ile simante edildi ve kole bölgesinde ki fazla siman temizlendikten sonra teleskop tutuculu protez ve deflex protez teslim edildi (Resim 6). Hastanın 24 saat sonraki kontrol seansın da teleskop tutuculu protez çıkartılıp kalan siman artıkları temizlendi, mukoza irritasyonunun varlığı kontrol edildi. Hastaya protezin takılıp çıkartabilmesi için eğitim verildi. Periyodik kontrol randevuları yapılmıştır.

18 ay boyunca klinik ve radyografik olarak yapılan periyodik incelemeler sonucunda destek dişlerde periodontal bir sorun ile karşılaşılmamıştır. Hasta, protezin estetiğinden ve tutuculuğundan memnun olduğunu bildirmiştir.

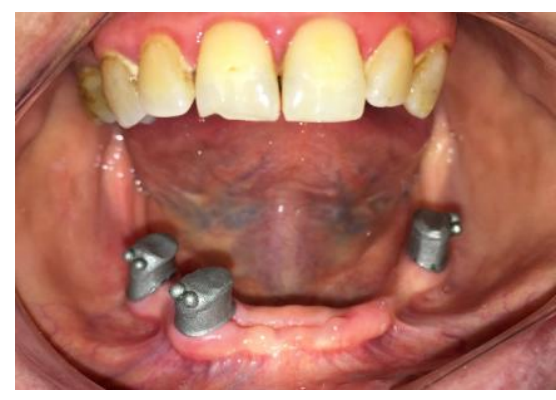

Resim 3. Primer kuronun provası

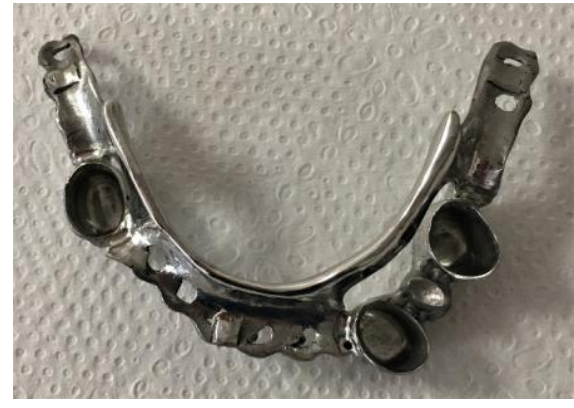

Resim 4. Sekonder kuronları splintleyen metal iskelet

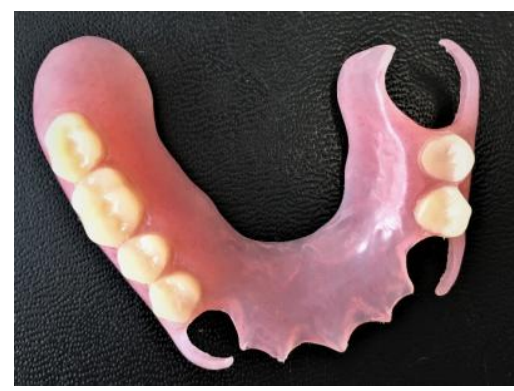

Resim 5. Üst çene deflex protez'in bitimi 


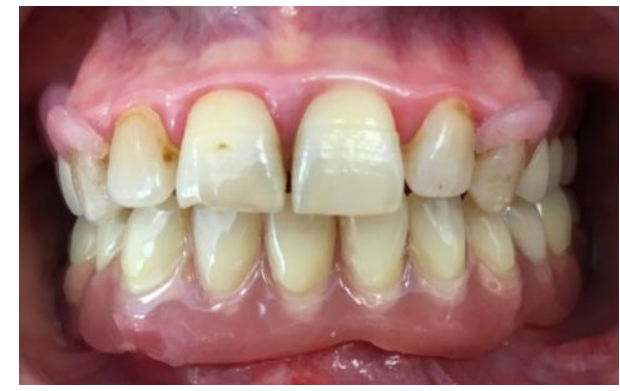

Resim 6. Bitmiş protezin ağız içi görüntüsü

\section{TARTIŞMA}

Kemoterapi ve radyoterapi tedavisi görmüş hastalar da tedavi alternatifleri kısıtılıdır. Tedavi planlaması aşamasında sabit ve hareketli protezlere alternatif olarak teleskop tutuculu hareketli bölümlü protez seçeneği de sunulmuştur. Hastamızın sistemik durumu sebebiyle implant üstü sabit ve hareketli protez seçeneği ilk planda düşünülmemiştir. Hastanın estetik ihtiyacı da göz önüne alındığında teleskobik tutuculu protezlerin başarısı göz ardı edilemez. Overdenture protez sınıfına giren teleskobik tutuculu protezler desteğin görünmemesi, periodontal sağlığın korunması, destek dişe gelen kuvvetin dişin uzun aksına paralel iletilmesi, tamir kolaylığının olması gibi avantajlarıyla doğru seçilmiş vakalarda alternatif bir tedavi yaklaşımıdır ${ }^{3,8,9}$. Fakat yapım aşamalarının daha hassas işlemler gerektirmesi, yapım süresinin uzun olması, kısmen daha pahalı olması gibi dezavantajları da mevcuttur ${ }^{10}$. Teleskop kuronların direkt tutucu olarak kullanılacağı bölümlü 5-10 yıllık uzun dönemli takibi olan çalışmalar TTP'lerin kroşeli HBP ve hassas bağlantılı protezlerle kıyaslandığında daha az kayıp gösterdiğini belirtmektedir ${ }^{11}$.

Widbom ve arkadaşlarının ${ }^{2}$, Wöstmann ve arkadaşlarının $^{4}$ yaptıkları 3-5 yıllık takipli klinik çalışmalar neticesinde destek dişlerdeki kayıp oranının sırasıyla \%7 ve \%3.8 olduğunu bildirmişlerdir.

Wöstmann ve arkadaşlarının ${ }^{4}$ yaptıkları 5 yıllık takip sonucunda protezlerin ve dayanak dişlerin sağ kalım oranı \%95 tir. Protezlerin dörtte birinde fasial tamir, üçte birinde astarlama ihtiyaçları olmuştur. Beşte birinde ise primer kuronda desimantasyon ortaya çıkmıştır.

Saito ve arkadaşları $^{12}$ rijit hassas tutuculu, teleskopik kuron tutuculu ve kroşe tutuculu protezleri yaptıkları çalışmada destek dişte, protez kaidesinde oluşan stresleri karşılaştırmışlardır. Bu çalışmanın sonuçlarına göre son destek dişte rijit hassas tutuculu ve teleskopik tutuculu protezler, kroşe tutuculu protezlere göre daha fazla stres oluşturmaktadırlar. Fakat hassas tutuculu protezler teleskobik protezlere göre daha fazla stres oluşturmaktadır. Protez kaidesindeki stres ise stabilitesi ve retansiyonu fazla olduğundan dolayı rijit hassas tutuculu ve teleskop tutuculu protezde kroşe tutuculu proteslere göre daha azdır.

Hosny ve arkadaşları ${ }^{13}$ bağlantı tipinden bağımSIz olarak başarılı klinik sonuçlar bildirilmesine rağmen dişlerin intrüze olması gibi majör problemler de bildirilmiştir. Fakat arkadaşları ${ }^{14}$ sundukları vakanın bir yıllık klinik ve radyografik takibinde dişte intrüzyona rastlamadıklarını bildirmişlerdir.

Hoffmann ve arkadaşları ${ }^{15}$ bu tür olguların protetik rehabilitasyonunda diğer bağlantı sistemlerine göre teleskobik tutuculu sistemler daha başarılı sonuçlar vereceğini belirtmişlerdir. Yine aynı çalışmada bu başarının diş hekiminin klinik tecrübesine de bağlı olduğu bildirilmiştir.

Bazı araştırmacılar teleskobik tutucuları rijit tutucular olarak kabul etmekte ve proteze gelen çiğneme kuvvetleri dişler yardımıyla çene kemiğine iletilir. Bundan dolayı ki uzun dönem de proteze hiçbir işlem yapılmadan kullanılabilir ${ }^{16}$.

$\mathrm{Bu}$ olgu bildiriminde alt ve üst parsiyel dişsizlik vakasının üst çenesi estetik kaygıdan dolayı poliamid kaideli (deflex) bölümlü protez, alt çenesi ise teleskobik tutuculu hareketli protez ile tedavisi yapılmıştır. 18 aylık periyodik klinik ve radyografik kontrollerin sonuçları tatmin edicidir. Hastamızda teleskobik tutuculu alt protezi çıkartma problemi yaşanmıştır. Protezi çıkartabilmesi için kliniğimizde egzersizler yapılmıştır. Sonrasında protezini rahatlıkla çıkarttığı gözlemlenmiştir. Bunun dışında herhangi bir problem görülmemiştir.

Harun Reşit Bal: ORCID ID:00000003 18759464 Nuran Yanıkoğlu: ORCID ID: 0000000176771248

\section{KAYNAKLAR}

1. Türk $Y$, Işık G. Üst parsiyel dişsizlik vakasının teleskop tutuculu hareketli parsiyel protez ile tedavisi: olgu sunumu. İstanbul Ünivi Dişhek Fak Derg 2008; Sayı: 1-2: 41-4. 
2. Widbom T, Lofquist $L$, Widbom $C$, Soderfeldt B, Kronstrom M. Tooth-supported telescopic crownretained dentures: an up to 9-year retrospective clinical follow-up study. Int J Prosthodont 2004; 17:29-34.

3. Prakash V, Parkash H, Gupta R. Fixed removable prosthesis employing Marburg double crown system. J Indian Prosthodont 2008; 8:59-62.

4. Wöstmann B, Balkenhol M, Weber A, Ferger $P$, Rehmann $\mathrm{P}$. Long-term analysis of telescopic crown retained removable partial dentures: Survival and need for maintenance. J Prosthet Dent 2007; 35:939-45.

5. Langer A. Telescope retainers for removable partial dentures. J Prosthet Dent 1981; 45:37-43.

6. Langer A. Telescope retainers and their clinical application. J Prosthet Dent, 1980; 44:516-22.

7. Langer $Y$, Langer A. Tooth-supported telescopic prostheses in compromised dentitions: A clinical report. J Prosthet Dent 2000; 84:129-32.

8. Wenz HJ, Hertrampf K, Lehmann K. Clinical longevity of removable partial dentures retained by telescopic crowns: outcome of the double crown with clearence fit. Int J Prosthodont 2001; 14:207-13.

9. Igarashi $Y$, Ogata $A$, Kuroiwa $A$, Wang $\mathrm{CH}$. Stress distribution and abutment tooth mobility of distalextension removable partial dentures with different retainers: an in vivo study. J Oral Reh 1999; 26:111-6.

10. Minagi S, Natsuaki N, Nishigawa G, Sato T. New telescopic crown design for removable partial dentures. J Prosthet Dent 1999; 81:684-8.

11. Beschnidt SM, Chitmongkolsuk S, Prull R. Telescopic crown-retained removable partial dentures: review and case report. Compend Contin Educ Dent 2001; 22: 927-8, 929-32, 93442.

12. Saito M, Miura $Y$, Notani K, Kawasaki T. Stress distribution of abutments and base displacement with precision attachment- and telescopic crownretained removable partial dentures. J Oral Reh 2003; 30: 482-7.
13. Hosny M, Duyck J, van Steenberghe D, Naert I. Within-subject comparison between connected and nonconnected tooth-to-implant fixed partial prostheses: up to 14-year follow-up study. Int J Prosthodont 2000; 13:340-6.

14. Geçkili O, Sönmez E, Bural C, Yıldız İ. Parsiyel dişsizliğin dental implantlar ve teleskop tutuculu protezler ile tedavisi: bir olgu sunumu. J Dent Fac Atatürk Uni 2012; 22:298-305

15. Hoffmann O, Beaumont C, Tatakis DN, Zafiropoulos GG. Telescopic crowns as attachments for implant supported restorations: a case series. J Oral Implant. 2006; 32:291-9.

16. Erken O, Kurtoğlu C, Hassas bağlantılar: Derleme. Atatürk Üniv Dis Hek Fak Derg 2008; 111-20

\section{Yazışma Adresi}

Dt. H. Reşit Bal

Atatürk Üniversitesi

Diş Hekimliği Fakültesi

Protetik Diş Tedavisi AD.

ERZURUM

TIf: +90 $4422360944-1751$

Fax: +904422360945

E-mail: dtharunbal@gmail.com 